\title{
Evaluation of expression levels and mechanism of complement activation
}

\author{
XING WANG $^{1}$, AN-HENG LIU ${ }^{2}$, ZHONG-WEI JIA ${ }^{1}$, KUI PU ${ }^{1}$, KANG-YIN CHEN ${ }^{3}$ and HUA GUO ${ }^{4}$ \\ ${ }^{1}$ Department of Cardiology, The 254th Hospital of PLA, Tianjin 300142; ${ }^{2}$ Department of Cardiology, \\ The Fourth Affiliated Hospital of Tianjin Medical University; ${ }^{3}$ Department of Cardiology, The Affiliated Hospital \\ of Tianjing Medical University, Tianjin 300070; ${ }^{4}$ Department of Geriatric Medicine, \\ The 254th Hospital of PLA, Tianjin 300142, P.R. China
}

Received January 23, 2017; Accepted May 12, 2017

DOI: $10.3892 /$ etm.2017.4841

\begin{abstract}
The present study aimed to reveal the expression changes of complement system activation and complement activation product $\mathrm{C} 3$ a receptor during acute myocardial infarction. Blood samples were collected from healthy individuals and from patients with coronary artery stenosis or acute myocardial infarction. The subjects received physical examination in hospital between January and July 2015 (n=5). Cytometric bead array was performed to measure the levels of complement system activation product anaphylatoxin $\mathrm{C} 3 \mathrm{a}$, $\mathrm{C} 4 \mathrm{a}$ and $\mathrm{C} 5 \mathrm{a}$. Immunohistochemical investigations were performed in tissues of patients who underwent coronary artery bypass grafting between January and July 2015 to detect the expression of $\mathrm{C} 3$ a receptor. The results of cytometric bead array showed that the content of complement activation products $\mathrm{C} 3 \mathrm{a}, \mathrm{C} 4 \mathrm{a}$ and $\mathrm{C} 5 \mathrm{a}$ in the plasma of patients with coronary artery stenosis and acute myocardial infarction were significantly higher than those of the control group $(\mathrm{P}<0.01)$. The results of immunoblotting suggested that the protein expression of $\mathrm{C} 3 \mathrm{a}$ receptor in infarct tissues of patients with acute myocardial infarction was significantly higher than that of normal tissues adjacent to the infarcted area $(\mathrm{P}<0.05)$. There is complement system activation in patients with acute myocardial infarction. Additionally, the increase in the expression of complement $\mathrm{C} 3$ a receptor in tissues of infarct area suggested that $\mathrm{C} 3 \mathrm{a}-\mathrm{C} 3 \mathrm{a}$ receptor signaling pathway may be involved in the development of myocardial infarction.
\end{abstract}

\section{Introduction}

Acute myocardial infarction is the most common aorta syndrome with high mortality and acuteness $(1,2)$. Myocardial

Correspondence to: Dr Hua Guo, Department of Geriatric Medicine, The 254th Hospital of PLA, 60 Huangwei Road, Tianjin 300142, P.R. China

E-mail: jiangbai624915@163.com

Key words: complement system, C3a receptor, acute myocardial infarction infarction involves deceptive lumen formation by blood penetration to intima and access to aorta. This could induce fatal complications such as rupture and cardiac tamponade. The typical clinical manifestation is sudden lancination of lower back, where the occurrence does not exceed 14 days $(3,4)$. The main pathology manifests as retrogression of artery medial and infiltration of inflammatory cells $(3,5)$. In mouse, the application of anti-neutrophil cytoplasmic antibody may markedly reduce the occurrence of acute myocardial infarction (6).

Results of a previous study showed that activation of the complement system resulted in the collection of inflammatory cells on the diseased region (7). The mouse model with coronary artery stenosis demonstrated that there is complement system activation (8-11). However, the mechanism of the complement system in acute myocardial infarction remains to be determined. The aim of the present study was to study the complement system activation and complement $\mathrm{C} 3$ a receptor expression in patients with acute myocardial infarction. The present study provided a theoretical basis for the investigation of anaphylatoxin $\mathrm{C} 3 \mathrm{a}$ and the function of its recptor during acute myocardial infarction.

\section{Materials and methods}

Clinical blood samples. Five patients who accepted ascending aorta replacement operation and five patients with coronary artery stenosis before operation were collected in our hospital between January and July 2015 as per ethics approval of the 254th Hospital of PLA. The average ages of the subjects ranged from $55 \pm 6.54$ to $49.4 \pm 3.2$ years. The diagnostic criteria of acute myocardial infarction were as follows: CT angiography showed that dissection diaphragm divided aorta into true lumen and false lumen (3). The diagnostic criteria of coronary artery stenosis were the pathological expansion of abdominal aorta exceeding $50 \%$ of normal blood vessel diameter (12). All the patients underwent preoperative examination including ultrasonic cardiogram and signed informed consent after postoperative pathology identification. The blood preparations were collected in EDTA anticoagulative tube, which was kept at $4^{\circ} \mathrm{C}$ for transient preservation. The supernatant was removed within $8 \mathrm{~h}$ and stored at $-80^{\circ} \mathrm{C}$. 
Table I. Clinical characteristics of patients with AMI.

\begin{tabular}{lcccc}
\hline & $\begin{array}{c}\text { Age } \\
\text { (years) }\end{array}$ & Sex & $\begin{array}{c}\text { On site days } \\
\text { of AMI }\end{array}$ & Hypertension \\
\hline 1 & 59 & Male & 3 & + \\
2 & 44 & Male & 1 & + \\
3 & 51 & Male & 2 & - \\
4 & 60 & Female & 3 & - \\
5 & 61 & Male & 5 & + \\
\hline
\end{tabular}

AMI, acute myocardial infarction.

Clinical pathology samples. Five patients with infarcted myocardium who received coronary artery bypass grafting in hospital between January and July 2015 were collected, average age of $55 \pm 6.54$ years, with ascending aorta inner diameter of $42.2 \pm 1.47 \mathrm{~mm}$, and a morbidity average $2.8 \pm 1.33$ days (Table I). The diagnostic criteria of acute myocardial infarction included typical chest pain with sudden onset and long persistent period, located at the substernal area or precordium. The constriction pain was often accompanied by feeling of impending death, which is the typical symptom in diagnostic criteria of myocardial infarction. The typical evolution process of electrocardiogram in diagnostic criteria of myocardial infarction was followed. The change of serum enzymes included the sequence change of serum enzyme concentration or beginning at first and reducing later on, which was a typical evolution process of myocardial infarction. Six hours after on site, serum creatin phosphokinase (CK or $\mathrm{CPK}$ ) appeared and reached a peak at $24 \mathrm{~h}$, and disappeared after $48-72 \mathrm{~h}$, with a positive rate of $92.7 \%$ (3). Before surgery, the patients were examined by coronary angiogram and diagnosed as acute myocardial infarction. Stent intervention operation could not be performed. After operation, the patients were verified by pathology and signed informed consent. A section of the cut tissue sample was placed into a cryopreserved tube directly and reserved in liquid nitrogen, while the other section was fixed in $4 \%$ paraformaldehyde and paraffin-embedded.

Main reagents and apparatus. Antibodies used in the study were: Anti-GAPDH antibody (Beijing Zhongshan Golden Bridge Biotechnology Co., Ltd., Beijing, China), anti-C3aR antibody (Abcam, Cambridge, UK), and infrared dye conjugate secondary antibody (Rockland Immunochemicals, Inc., Gilbertsville, PA, USA). Reagents and consumable items were: tissue protein lysate, protease inhibitor, phosphatase inhibitor, EDTA, BCA protein assay kit, protein marker (Thermo Fisher Scientific, Inc., Waltham, MA, USA), PVDF film (Millipore Corp., Billerica, MA, USA), and human anaphylatoxin cytometric bead array kit (BD Biosciences, San Diego, CA, USA). Apparatus used in the present study included, tissue homogenizer, multi-wavelength ELISA (PerkinElmer, Inc., Waltham, MA, USA), protein electrophoresis apparatus and transmembrane groove (Bio-Rad, Berkeley, CA, USA), Odyssey infrared imaging system (Li-Cor BioSciences, Lincoln, NE, USA), and flow cytometry (BD Biosciences).
Quantitative analysis of anaphylatoxin levels in human plasma. Human anaphylatoxin CBA kit was used and manufacturer instructions were followed for the analyses.

Protein immunoblotting. Tissues (50-100 mg) of ascending aorta wall were kept in liquid nitrogen. A total of $500 \mu \mathrm{l}$ tissue lysate, $5 \mu \mathrm{l}$ protease inhibitor, phosphatase inhibitor and EDTA were added for each $50 \mathrm{mg}$. Protein extraction was conducted according to the reagent specification. The supernatant was absorbed and the protein concentration was detected by the BCA method. Spacer gel and separation gel were configured, with loading amount of $30 \mu \mathrm{g}$ for each well, standard protein marker of $5 \mu \mathrm{l}$, electrophoretic voltage of $60 \mathrm{~V}$ for spacer gel, electrophoretic voltage of $100 \mathrm{~V}$ for separation gel, under $300 \mathrm{~mA}$ constant current and transmembrane for $90 \mathrm{~min}$ to PVDF film, which was sealed for $1 \mathrm{~h}$ with $5 \%$ skim milk powder. After membrane cleaning, new sealing solution was used to dilute primary antibody by an appropriate proportion, which was incubated overnight at $4^{\circ} \mathrm{C}$. After membrane cleaning again, new sealing solution was used to dilute the second antibody that was marked by IR by the proportion of 1:10,000 and imaged in Odyssey infrared imaging system. Primary rabbit polyclonal C3aR antibody (dilution, 1:500; cat. no. ab126250) and secondary goat anti-rabbit (HRP) IgG antibody (dilution, 1:2,000; cat. no. ab6721) were purchased from Abcam (Cambridge, MA, USA).

Pathological section and immunohistochemically staining. Ascending aorta wall specimens were collected, respectively, from acute myocardial infarction group and normal control group, which underwent dehydration, transparency, wax dip, embedding and pathological section after $10 \%$ of formalin fixation of $5 \mu \mathrm{m}$. Immunohistochemical staining was performed and the analyses were done under a light microscope.

Statistical analysis. SPSS Statistics 17.0.0 (IBM Corp., Armonk, NY, USA) software was used to process experimental data. Measurement data are shown as mean \pm standard deviation and comparison was detected by t-test and analyzed by one-way analysis of variance. Dunnett's method was applied for pairwise comparison among three groups. $\mathrm{P}<0.05$ was considered to indicate a statistically significant difference.

\section{Results}

Increased anaphylatoxin level in plasma of patients with acute myocardial infarction. The study results showed that the levels of C3a, C4a and C5a in the plasma of patients with coronary artery stenosis were signficantly higher than those of the control group $(\mathrm{P}<0.01)$ (Fig. 1). The levels of $\mathrm{C} 3 \mathrm{a}, \mathrm{C} 4 \mathrm{a}$ and $\mathrm{C} 5 \mathrm{a}$ in the plasma of patients with acute myocardial infarction were also significantly higher as compared to the control group $(\mathrm{P}<0.01)$ (Fig. 1).

Increased C3Ar expression in human acute myocardial infarction specimens. The results showed that the protein expression of C3a receptor in infarct tissues of patients with acute myocardial infarction was significantly higher than that of normal control group (Fig. 2A), with statistical significant difference $(\mathrm{P}<0.05)$ (Fig. 2B). 
A

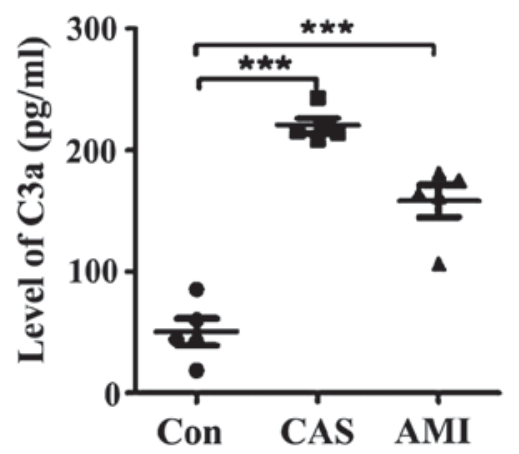

B

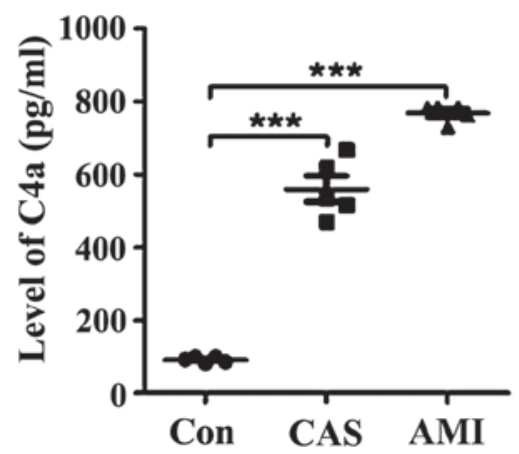

C

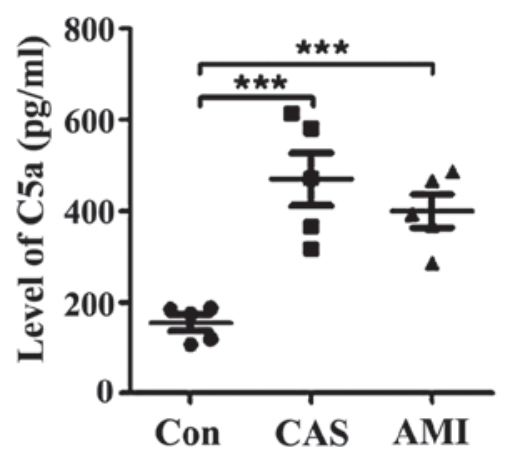

Figure 1. Activation of complement system in patients with acute myocardial infarction. Compared with the control group, both CAS and AMI increased significantly. ${ }^{* * * *} \mathrm{P}<0.001$. CAS, coronary artery stenosis; AMI, acute myocardial infarction.

A

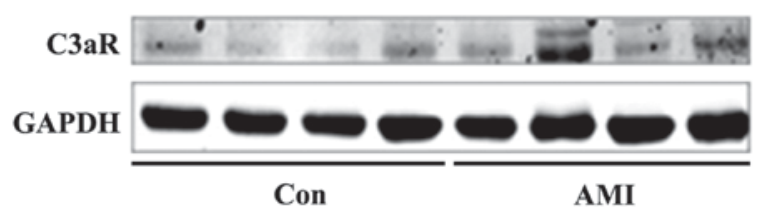

B

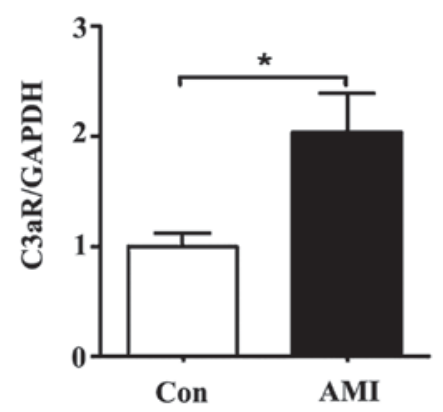

Figure 2. C3aR protein expression level in AMI. (A) Normal coronary artery and human coronary artery stenosis detected by protein immunoblotting, C3aR protein expression in acute myocardial infarction specimens (B) Statistical analysis was conducted by gray scanning. ${ }^{*} \mathrm{P}<0.05$. AMI, acute myocardial infarction.

Increased positive area of C3aR in human acute myocardial infarction specimens. The present study results suggested that, the number of brown particles of acute myocardial infarction were significantly higher as compared with normal infarcted myocardium ( $\mathrm{P}<0.001)$ (Fig. 3).

\section{Discussion}

The incidence rate of acute myocardial infarction is annually on the increase (13). The onset of this disease is extremely dangerous, and the postoperative hospital mortality rate may reach $32 \%$. At present, there is no effecitve drug treatment $(3,14)$. Therefore, effective prevention and cure of acute myocardial infarction has become an extremely urgent task, but the pathogenesis is not quite clear yet.

The existing documents hold that inflammatory cells play an important role in infarcted myocardium infiltration, while increased inflammatory cells could continue to damage myocardial tissue as well $(1,4,15)$. Therefore, the pathway and

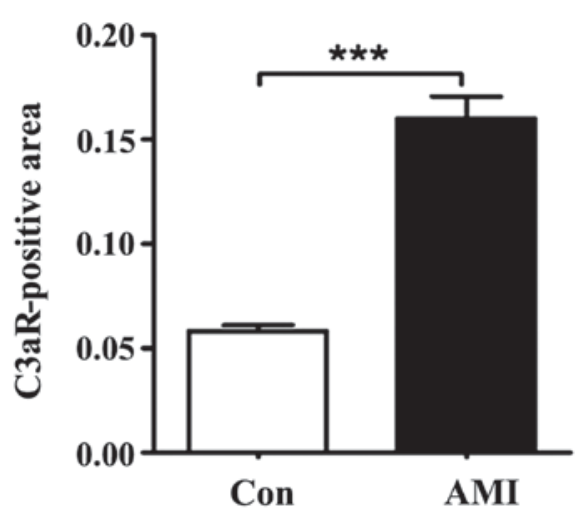

Figure 3. C3aR distribution in AMI. Positive area of C3aR was analyzed statistically. ${ }^{* * *} \mathrm{P}<0.001$. AMI, acute myocardial infarction.

molecule that induce inflammation infiltration may be involved in the occurrence and development of acute myocardial infarction. Three pathways may activate complement system via a typical, lectin and alternative pathway (7). As complement activation products, anaphylatoxin $\mathrm{C} 3 \mathrm{a}, \mathrm{C} 4 \mathrm{a}$ and $\mathrm{C} 5 \mathrm{a}$ have a strong pathogenous effect $(7,16,17)$. Recent reports suggested that the injured arterial wall may activate alternative pathway and lectin pathway of complement to promote the development of myocardial infarction in mouse with coronary artery stenosis model (8-11). In the present study, we detected a significant increase in the levels of C3a, C4a and C5a in the blood samples of patients with coronary artery stenosis. At the same time, we found that the levels of anaphylatoxin C3a, C4a and C5a in the plasma of patients with actute myocardial infarction were also increased markedly. This demonstrated activation of complement system which often exists during acute myocardial infarction.

The active fragment of $\mathrm{C} 3 \mathrm{a}$ requires receptor binding for its role. The expression of its receptor may also influence the activation of the downstream signal. Thus, we used immunoblotting and immunohistochemical staining to detect C3aR protein expression in infarcted myocardium tissue. The results showed that $\mathrm{C} 3 \mathrm{aR}$ was upregulated in acute myocardial infarction. At present, the results suggest that the activation of C3a-C3aR signal existed in myocardial infarction, in turn, it may activate inflammation signal to promote the generation of matrix metalloproteinase. This aggravates the formation 
and development of myocardial infarction. Previous findings showed that C3aR expressed in inflammatory cells (neutrophile granulocyte and macrophage) (18). We observed a high C3aR expression in patients with coronary artery stenosis by immunohistochemical staining, which suggested that it may play a role in myocardial cells. However, the cell types affected by $\mathrm{C} 3 \mathrm{a}-\mathrm{C} 3 \mathrm{aR}$ require further verification.

Inflammation plays an important role in the incidence and development of acute myocardial infarction, which has been accepted widely (3), and the intense inflammatory effect of complement system activation has been verified as well $(7,19)$. However, to the best of our knowledge, there is no report on the function of complement system in acute myocardial infarction. In the present study, high levels of anaphylatoxin C3a, $\mathrm{C} 4 \mathrm{a}$ and $\mathrm{C} 5 \mathrm{a}$ produced by complement activation of patients with acute myocardial infarction increased, and the high level sof C3aR of aorta wall suggested C3a-C3aR signal pathway might play an important role in the incidence and development of acute myocardial infarction. The present study provided a new possible patho-mechanism for the occurrence and rupture of myocardial infarction.

\section{References}

1. Ilczuk T, Wasiutynski A, Wilczek E and Gornicka B: The study of the protein complement in myocardial infarction. Immunol Lett 162: 262-268, 2014.

2. Wysoczynski M, Solanki M, Borkowska S, van Hoose P, Brittian KR, Prabhu SD, Ratajczak MZ and Rokosh G: Complement component 3 is necessary to preserve myocardium and myocardial function in chronic myocardial infarction. Stem Cells 32: 2502-2515, 2014.

3. Yan W, Che L, Jiang J, Yang F, Duan Q, Song H, Liu X, Shen Y and Wang L: Depletion of complement system immunity in patients with myocardial infarction. Mol Med Rep 14: 5350-5356, 2016.

4. Emmens RW, Wouters D, Zeerleder S, van Ham SM, Niessen HW and Krijnen PA: On the value of therapeutic interventions targeting the complement system in acute myocardial infarction. Transl Res 182: 103-122, 2017.

5. Horváth Z, Csuka D, Vargova K, Kovács A, Leé S, Varga L, Préda I, Tóth Zsámboki E, Prohászka Z and Kiss RG: Alternative complement pathway activation during invasive coronary procedures in acute myocardial infarction and stable angina pectoris. Clin Chim Acta 463: 138-144, 2016.

6. Hammarsten O, Theodorsson E, Bjurman C and Petzold M: Risk of myocardial infarction at specific troponin $\mathrm{T}$ levels using the parameter predictive value among lookalikes (PAL). Clin Biochem 50: 6-10, 2017.
7. Johnston N, Bodegard J, Jerström S, Åkesson J, Brorsson H, Alfredsson J, Albertsson PA, Karlsson JE and Varenhorst C: Effects of interactive patient smartphone support app on drug adherence and lifestyle changes in myocardial infarction patients: A randomized study. Am Heart J 178: 85-94, 2016.

8. Prabhu SD and Frangogiannis NG: The biological basis for cardiac repair after myocardial infarction: From inflammation to fibrosis. Circ Res 119: 91-112, 2016.

9. Mott B, Packwood W, Xie A, Belcik JT, Taylor RP, Zhao Y, Davidson BP and Lindner JR: Echocardiographic ischemic memory imaging through complement-mediated vascular adhesion of phosphatidylserine-containing microbubbles. JACC Cardiovasc Imaging 9: 937-946, 2016.

10. Ding S, Yang Y and Mei J: Protective effects of L-Malate against myocardial ischemia/reperfusion injury in rats. Evid Based Complement Alternat Med 2016: 3803657, 2016.

11. Emmens RW, Baylan U, Juffermans LJ, Karia RV, Ylstra B, Wouters D, Zeerleder S, Simsek S, van Ham M, Niessen HW and Krijnen PA : Endogenous C1-inhibitor production and expression in the heart after acute myocardial infarction. Cardiovasc Pathol 25: 33-39, 2016.

12. Vuohelainen V, Paavonen T, Hamalainen M, Moilanen E and Mennander AA: C4d deposition reveals myocardial infarction after cardiac arrest - Experimental study. Adv Clin Exp Med 24: 393-399, 2015.

13. Hertle E, Arts IC, van der Kallen CJ, Feskens EJ, Schalkwijk CG, Stehouwer CD and van Greevenbroek MM: The alternative complement pathway is longitudinally associated with adverse cardiovascular outcomes. The CODAM study. Thromb Haemost 115: 446-457, 2016.

14. Fordjour PA, Wang Y, Shi Y, Agyemang K, Akinyi M, Zhang Q and Fan G: Possible mechanisms of C-reactive protein mediated acute myocardial infarction. Eur J Pharmacol 760: 72-80, 2015.

15. Patzelt J, Verschoor A and Langer HF: Platelets and the complement cascade in atherosclerosis. Front Physiol 6: 49, 2015.

16. Al-Numair KS, Chandramohan G, Alsaif MA, Veeramani C and El Newehy AS: Morin, a flavonoid, on lipid peroxidation and antioxidant status in experimental myocardial ischemic rats. Afr J Tradit Complement Altern Med 11: 14-20, 2014.

17. Keizer MP, Pouw RB, Kamp AM, Patiwael S, Marsman G, Hart MH, Zeerleder S, Kuijpers TW and Wouters D: TFPI inhibits lectin pathway of complement activation by direct interaction with MASP-2. Eur J Immunol 45: 544-550, 2015.

18. Zhang L, Bell BA, Yu M, Chan CC, Peachey NS, Fung J, Zhang X, Caspi RR and Lin F: Complement anaphylatoxin receptors $\mathrm{C} 3 \mathrm{aR}$ and $\mathrm{C} 5 \mathrm{aR}$ are required in the pathogenesis of experimental autoimmune uveitis. J Leukoc Biol 99: 447-454, 2016.

19. Jiang M, Kang L, Wang Y, Zhao X, Liu X, Xu L and Li Z: A metabonomic study of cardioprotection of ginsenosides, schizandrin, and ophiopogonin D against acute myocardial infarction in rats. BMC Complement Altern Med 14: 350, 2014. 